\title{
Implementasi RESTful API dalam Pembuatan Master Data Planogram Menggunakan Framework Flask dan Metode SDLC (Studi Kasus: PT Sumber Alfaria Trijaya, Tbk)
}

\author{
RESTful API Implementation in Master Data Planogram Development using the Flask \\ Framework (Case Study: PT Sumber Alfaria Trijaya, Tbk) \\ Era Susanti ${ }^{1}$, Evangs Mailoa ${ }^{2}$ \\ ${ }^{1,2}$ Program Studi Teknik Informatika Fakultas Teknologi Informasi, \\ Universitas Kristen Satya Wacana \\ E-mail: 1672016309@student.uksw.edu, 2evangs.mailoa@uksw.edu
}

\begin{abstract}
Abstrak
Salah satu perusahaan ritel yang sedang berkembang dan merupakan salah satu perusahaan ritel terbesar di Indonesia yaitu Alfamart yang dimiliki oleh PT. Sumber Alfaria Trijaya, Tbk. Alfamart harus memiliki strategi pemasaran yang terbaik serta meningkatkan inovasi demi kepuasan para pelanggan agar dapat bertahan dalam persaingan bisnis yang tinggi. Salah satu strategi dalam meningkatkan pemasaran yaitu penataan display produk yang ada pada toko yang dikenal dengan planogram. Planogram merupakan suatu konsep yang digunakan dalam perencanaan penataan dan penempatan produk sesuai dengan kategori tertentu berdasarkan kebiasaan belanja konsumen yang bertujuan meningkatkan penjualan pada ritel. Penelitian ini dilakukan untuk membuat aplikasi master data planogram berbasis web menggunakan framework Flask dengan bahasa pemrograman python. Metode yang digunakan pada penelitian ini adalah RESTful API yaitu implementasi dari web service yang bekerja melalui link HTTP. Penelitian ini menghasilkan sebuah aplikasi master data berbasis web yang dapat digunakan oleh user dalam memasukkan data-data yang dibutuhkan dalam pembuatan planogram.
\end{abstract}

Kata Kunci : RESTful API, Python Flask, Planogram

\begin{abstract}
One of developing retail company and is one of the biggest retail companies in Indonesia, namely Alfamart which is owned by PT. Sumber Alfaria Trijaya, Tbk. Alfamart must have the best marketing strategy and increase innovation for the satisfaction of customers in order to survive in high business competition. One strategy to improve marketing is the arrangement of product displays in stores known as planograms. Planogram is a concept that is used in planning the arrangement and placement of products according to certain categories based on consumer spending habits that aim to increase sales at retail. This research was conducted to create a web-based planogram master application using the Flask framework with the python programming language. The method used in this study is the RESTful API, which is the implementation of web services that work through HTTP links. This research produces a web-based master data application that can be used by users in entering data needed in making a planogram.
\end{abstract}

Keywords: RESTful API, Python Flask, Planogram

\section{PENDAHULUAN}

Perkembangan teknologi yang terjadi pada suatu negara dapat pula mempengaruhi perkembangan di bidang lain seperti pertumbuhan ekonomi. Salah satu aspek yang mendukung perkembangan ekonomi saat ini yaitu semakin bertambahnya usaha ritel yang bermunculan. Ritel 
merupakan bidang bisnis yang menjual produk dan jasa yang diberi nilai tambah guna memenuhi kebutuhan pribadi, keluarga maupun kelompok dalam jumlah eceran. Ritel menjadi mata rantai terakhir terakhir proses distribusi yang menghubungkan produsen dengan konsumen. Merupakan salah satu indikator ekonomi yang memberikan kontribusi sebesar 19-31\% terhadap PDRB (Pendapatan Domestik Regional Bruto) [1].

Salah satu ritel yang sedang berkembang maju di Indonesia yaitu Alfamart. Alfamart merupakan brand minimarket yang menyediakan kebutuhan sehari-hari yang dimiliki oleh PT. Sumber Alfaria Trijaya, Tbk. Merupakan salah satu perusahaan ritel terbesar di Indonesia yang berdiri pada tahun 1989 dan memulai bisnis di bidang perdagangan dan distribusi seperti barangbarang konsumsi, kemudian pada tahun 1999 masuk ke sektor ritel [2]. Dalam menghadapi persaingan bisnis yang tinggi tentunya Alfamart harus memiliki strategi pemasaran yang baik dan menarik serta meningkatkan inovasi demi kepuasan para pelanggan [3]. Salah satu cara dalam meningkatkan strategi pemasaran dalam ritel yaitu melalui penataan produk yang ada di toko karena dapat meningkatkan minat beli pelanggan. Implementasi penataan dan display produk pada ritel yaitu planogram.

Planogram merupakan suatu konsep yang digunakan dalam perencanaan penataan dan penempatan produk sesuai dengan kategori tertentu berdasarkan kebiasaan belanja konsumen yang bertujuan meningkatkan penjualan pada ritel [4]. Planogram dibuat dengan tujuan memaksimalkan penjualan pada retail.

Penelitian ini dilakukan untuk membuat master data planogram pada aplikasi marketing berbasis web menggunakan framework Flask dengan bahasa pemrograman yang ringan dan banyak dipakai saat ini yaitu python.

Penelitian ini menghasilkan sebuah aplikasi master data berbasis web yang dapat digunakan oleh user yaitu bagian marketing dalam memasukkan data-data yang dibutuhkan dalam pembuatan planogram. Data-data yang diinputkan meliputi data jenis lokasi, data type toko, ukuran rak, kelas produk posisi rak, rak non reguler, nama regional dan regional transfer plano. Hasil penelitian ini dapat membantu memudahkan pengguna aplikasi yaitu bagian marketing dalam memanajemen data yang dibutuhkan saat pembuatan planogram.

Berdasarkan latar belakang yang telah diuraikan, maka identifikasi masalah dalam penelitian ini yaitu manajemen data master planogram sangat diperlukan untuk membantu dalam memasukkan data yang dibutuhkan dalam pengimplementasian planogram.

Berdasarkan latar belakang dan identifikasi masalah diatas, maka rumusan masalah pada penelitian ini adalah bagaimana mengimplementasikan metode RESTful API dalam pembuatan master data planogram dalam Marketing Application System, bagaimana penggunaan framework Flask dalam pembuatan master data planogram pada Marketing Application System.

Tujuan dari penelitian ini yaitu membangun aplikasi master data planogram berbasis web pada PT. Sumber Alfaria Trijaya, Tbk yang lebih ringan dan mempermudah dalam pengelolaan master data planogram. Adapun manfaat dalam penelitian ini yaitu membuat sebuah aplikasi master data berbasis web yang lebih ringan dan mudah dalam penggunaannya dan memudahkan user yaitu bagian marketing dalam memanajemen data yang dibutuhkan pada saat pembuatan planogram.

Terdapat beberapa penelitian terdahulu yang berkaitan dengan penelitian ini. Penelitian yang dilakukan oleh Haryanto dkk yang berjudul "Pengaruh Peletakan Display Produk Berdasarkan Prinsip 5R dan Planogram terhadap Peningkatan Penjualan: Studi Kasus pada Ritel X di Lamongan" ini bertujuan untuk mengidentifikasi strategi dalam penataan barang atau produk dan meningkatkan penjualan pada Ritel X serta meningkatkan kebiasaan baik bagi karyawan dalam hal penyusunan produk. Hasil penelitian ini berdasarkan konsep 5R dan planogram. Pada penelitian ini data-data planogram yang dibuat masih menggunakan cara manual atau biasa yaitu menggunakan pareto chart [4].

Penelitian yang dilakukan oleh Gilang yang berjudul "Perancangan dan Implementasi Web Service sebagai Media Pertukaran Data pada Aplikasi Permainan" ini membahas tentang penerapan web service dalam pertukaran informasi pada platform yang berbeda antara website PHP dengan aplikasi android menggunakan Java. Modul yang dibuat pada penelitian ini yaitu modul register dan login, modul poin dan modul tukar pulsa. Pengujian modul pada penelitian ini menggunakan 
postman. Hasil dari penelitian ini yaitu web service dapat diimplementasikan dan dapat berjalan baik sesuai simulasi pada postman [5].

Penelitian yang dilakukan oleh Mukhammad dkk yang berjudul "Analisis dan Perancangan Representational State Transfer (REST) Web Service Sistem Informasi Akademik STT Terpadu Nurul Fikri Menggunakan YII Framework" ini menghasilkan REST web service sistem informasi akademik pada STT Terpadu Nurul Fikri yang menyediakan layanan bagi sistem lain yang membutuhkan dan menangani pertukaran data pada platform yang berbeda. Penelitian ini dibuat menggunakan Yii Framework 2.0. Pengujian sistem pada penelitian ini dilakukan menggunakan metode blackbox [6].

Keterkaitan penelitian ini dengan penelitian-penelitian sebelumnya yaitu pada penelitian sebelumnya data-data planogram masih dibuat secara manual menggunakan chart, kemudian pada penelitian lain menggunakan metode web service sebagai layanan bagi sistem lain dan pertukaran data pada platform yang berbeda, sedangkan pada penelitian ini data-data planogram dibuat dalam sebuah aplikasi berbasis web menggunakan sebuah framework yaitu Flask yang berbasis bahasa python dan web service pada penelitian ini digunakan sebagai implementasi metode membuat datadata planogram.

\section{METODE PENELITIAN}

Terdapat beberapa tahapan dalam penelitian ini agar pembuatan aplikasi berbasis web sesuai dengan hasil yang diharapkan. Pada penelitian ini menggunakan metode SDLC (System Development Life Cycle) Waterfall. Tahapan dalam penelitian ini yaitu sebagai berikut :

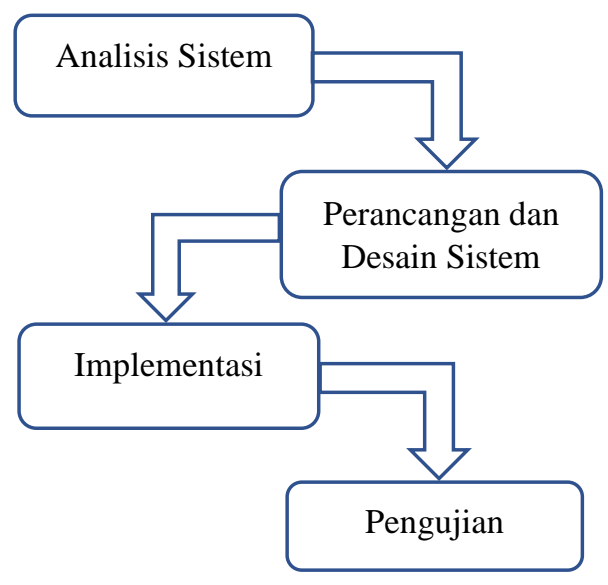

Gambar 1. Tahapan Metodologi Penelitian

Berikut ini merupakan penjelasan tahapan penelitian pada gambar 1 :

a. Analisis Sistem

Tahap ini merupakan tahap analisis kebutuhan sistem yang digunakan dalam penelitian ini. Analisis yang dilakukan yaitu bagaimana sistem yang berjalan pada penelitian ini dan apa saja yang dapat dilakukan oleh aktor dalam penelitian ini.

\section{b. Perancangan dan Desain Sistem}

Pada tahap ini akan dilakukan perancangan sistem berdasarkan analisis kebutuhan sistem yang telah dilakukan. Kemudian sistem yang telah dirancang dan dianalisis akan diimplementasikan menggunakan tools yaitu bahasa python dengan framework Flask dan database PostgreSQL. Tahap ini juga merupakan tahap pembuatan pemodelan sistem menggunakan UML (Unified Modeling Language). Pembuatan model sistem menghasilkan Use Case Diagram dan Activity Diagram. 


\section{c. Implementasi}

Tahap ini merupakan tahap pengimplementasian perancangan sistem yang telah dibuat. Tahap ini merupakan proses paling penting yang ada dalam metodologi penelitian ini karena inti dari pembuatan sistem ada pada tahap ini. Pembuatan sistem berdasarkan perancangan dan desain sistem yang telah dibuat pada tahap sebelumnya. Dalam implementasi penelitian ini menggunakan metode RESTful API yaitu implementasi dari web service yang bekerja melalui link HTTP [7]. Fungsi HTTP yang dapat digunakan pada REST yaitu fungsi get, post, put dan delete [7]. Pertama kali diperkenalkan oleh Roy Fielding pada tahun 2000. Sistem web service yang menerapkan prinsipprinsip REST disebut RESTful. Cara kerja dari RESTful yaitu client mengirim sebuah permintaan melalui HTTP Request dan server menanggapi permintaan client melalui HTTP Response. Terdapat 2 bagian pesan untuk berkomunikasi dengan server yaitu pesan header dan pesan body. HTTP header merupakan catatan kecil setiap transaksi pada HTTP sedangkan HTTP body yaitu data yang akan dikirimkan [8].

\section{d. Pengujian}

Tahap ini merupakan tahap pengujian terhadap aplikasi yang telah dibuat, apakah sesuai dengan rancangan awal sistem dan memastikan semua fungsi-fungsi yang terdapat didalamnya dapat berjalan dengan baik. Pengujian merupakan tahap yang penting karena sebelum aplikasi akan digunakan oleh user atau pengguna harus dipastikan agar aplikasi dapat digunakan dengan baik dan tidak terdapat kesalahan-kesalahan atau bug didalamnya. Tahap ini juga menentukan kepuasan dari user ketika menggunakan aplikasi yang telah dibuat.

\section{HASIL DAN PEMBAHASAN}

Berikut ini merupakan hasil penelitian berdasarkan perancangan sistem yang telah dibuat :

\section{a. Analisis Sistem}

Sistem yang akan berjalan pada penelitian ini yaitu pengguna dapat melakukan fungsi CRUD (Create, Read, Update, Delete) dalam pengolahan data pada aplikasi ini. Fungsi tersebut dapat dilakukan pada modul-modul yang tersedia untuk pembuatan planogram yaitu modul Jenis Lokasi, Type Toko, Ukuran Shelve, Class Product, Rak Non Reguler, Nama Regional, Regional Transfer Plano dan Planogram. Pengguna dapat melakukan method get, post, put dan delete pada masing-masing modul tersebut. Aktor yaitu pihak yang terlibat dalam sistem aplikasi [9] pada penelitian ini adalah user, dimana dalam hal ini yang bertindak sebagai user yaitu karyawan.

b. Perancangan dan Desain Sistem

Berikut ini merupakan hasil pembuatan desain pada penelitian ini. 




Gambar 2. Use Case Diagram Data Jenis Lokasi, Type Toko, Ukuran Shelve, Class Product

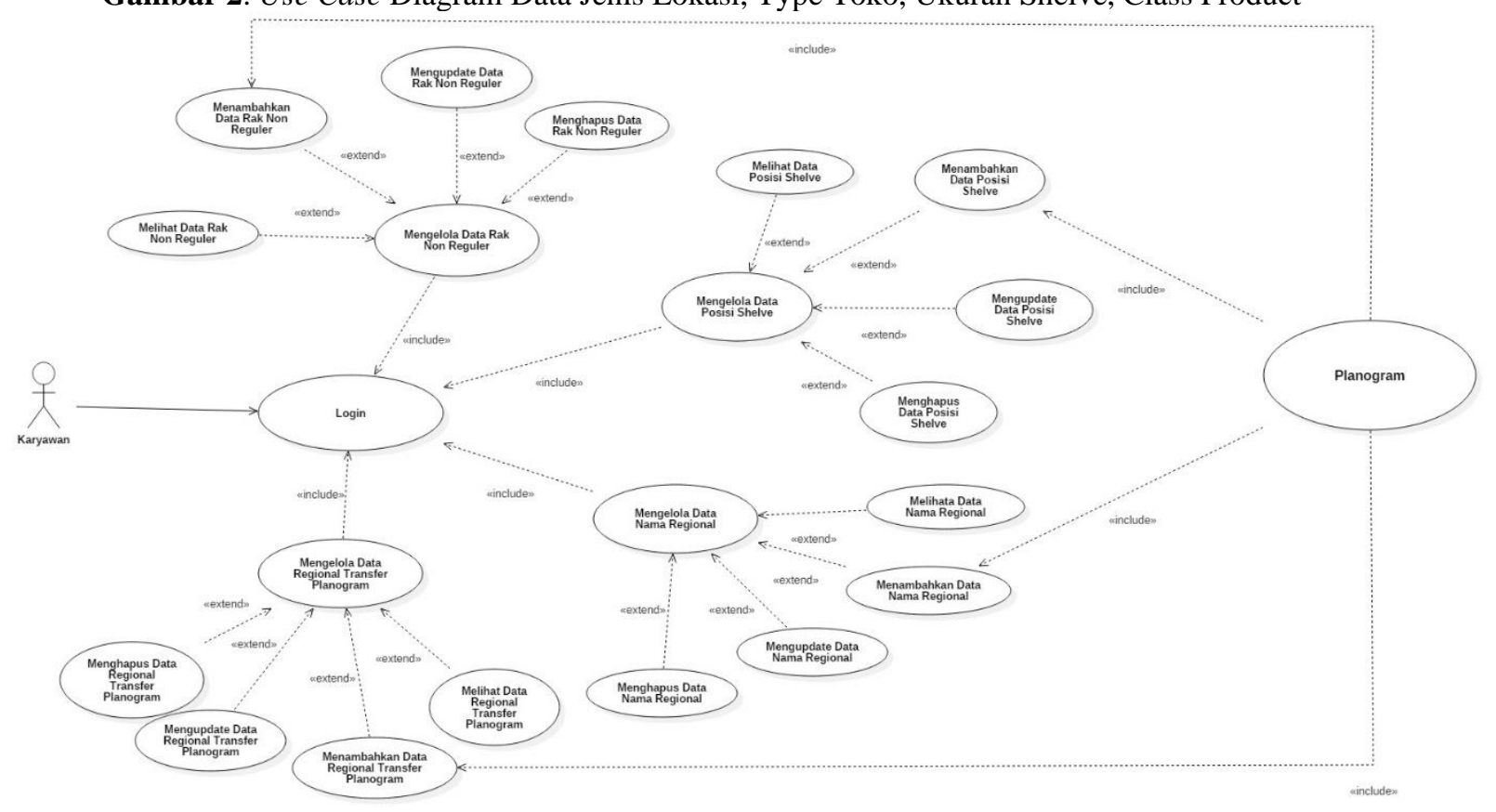

Gambar 3. Use Case Diagram Data Rak Non Reguler, Posisi Shelve, Nama Regional, Regional Transfer Plano

Gambar 2 dan 3 merupakan Use Case Diagram yang ada pada penelitian ini. Pada diagram tersebut karyawan berperan sebagai aktor yang akan menjalankan aplikasi. Pada gambar tersebut karyawan dapat menjalankan operasi pada beberapa modul. Sebelum menjalankan modul-modul tersebut karyawan harus melakukan login terlebih dahulu. Fungsi utama yang dapat dijalankan oleh karyawan yaitu pada Planogram, namun sebelum menjalankan fungsi pada planogram karyawan harus melakukan operasi pada modul-modul data master. Modul-modul data master yang dapat dijalankan oleh karyawan diantaranya yaitu mengelola data jenis lokasi, mengelola data type toko, mengelola data ukuran shelve, mengelola data class product, mengelola data rak non reguler, mengelola data posisi 
shelve, mengelola data nama regional dan mengelola data regional transfer plano. Dalam modul data master tersebut karyawan dapat melakukan fungsi pada masing-masing modul data master seperti melihat, menambahkan, mengedit dan menghapus data. Kemudian setelah melakukan operasi pada modul data master karyawan dapat menjalankan modul planogram dimana data planogram ini didapat dari modul-modul data master.

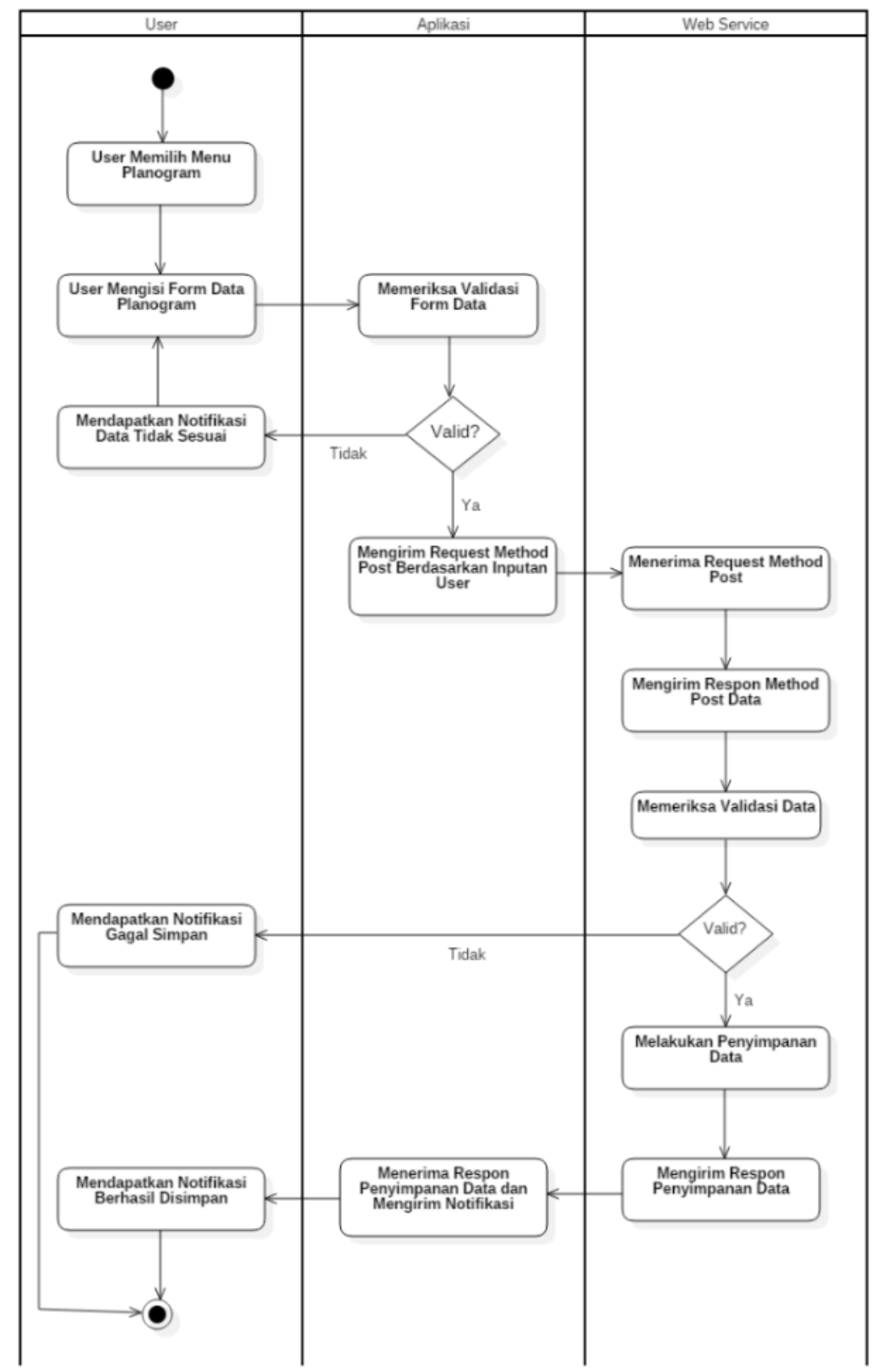

Gambar 3. Activity Diagram

Gambar 3 merupakan Activity Diagram pada penelitian ini yaitu pada menu Planogram proses insert data. Alur dari diagram ini yaitu langkah awal user memilih menu Planogram kemudian untuk menginsert data langkah selanjutnya user mengisi form data yang diperlukan untuk menginsert data. Setelah user mengisi form, aplikasi akan memeriksa validasi inputan form dari user jika input data valid maka aplikasi akan mengirim request method post berdasarkan inputan user tersebut, jika input data tidak valid maka user akan mendapatkan notifikasi jika data yang diisi tersebut tidak sesuai dan 
user harus mengisi ulang form tersebut sampai data dinyatakan valid. Setelah aplikasi mengirim request method post maka web service akan menerima request tersebut dan mengirim respon method post, kemudian web service akan memeriksa validasi data yang akan diinsert tersebut jika data tidak valid maka user akan mendapatkan notifikasi gagal menyimpan data, jika data valid maka web service akan melakukan penyimpanan data dan mengirim respon penyimpanan data. Setelah web service mengirim respon, aplikasi akan menerima respon data dan mengirim notifikasi, setelah itu user akan mendapatkan notifikasi data berhasil simpan.

c. Implementasi

Berdasarkan hasil perancangan sistem yang telah dibuat dan diimplementasikan menggunakan bahasa python dan framework flask, hasil penelitian ini yaitu aplikasi master data planogram berbasis web. Sistem ini dibangun menggunakan bahasa pemrograman python dengan framework flask dan database postgresql, sistem ini juga menggunakan metode restful API. Berikut ini merupakan hasil dari penelitian ini.

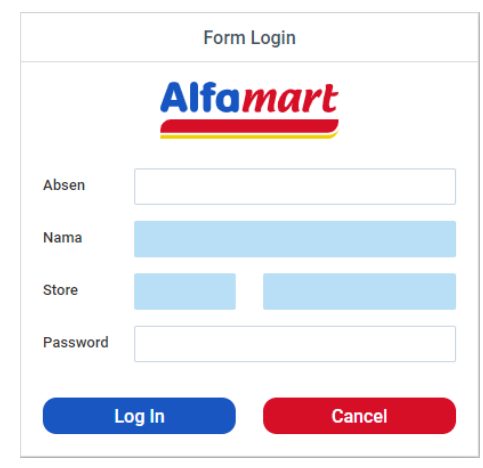

Gambar 4 Halaman Login

Gambar 4 merupakan halaman login. Pada saat login, user harus memasukkan absen atau id user dan password. Proses login ini yaitu ketika user memasukkan absen dan tekan enter maka jika data tersebut sesuai dengan database, pada kolom nama dan store secara otomatis terisi data sesuai inputan user tersebut, kemudian user memasukkan password dan klik tombol login. Jika data tersebut tidak sesuai dengan database maka akan muncul error handling dan user harus memasukkan kembali data yang benar. Jika login berhasil maka user akan masuk ke halaman utama web.

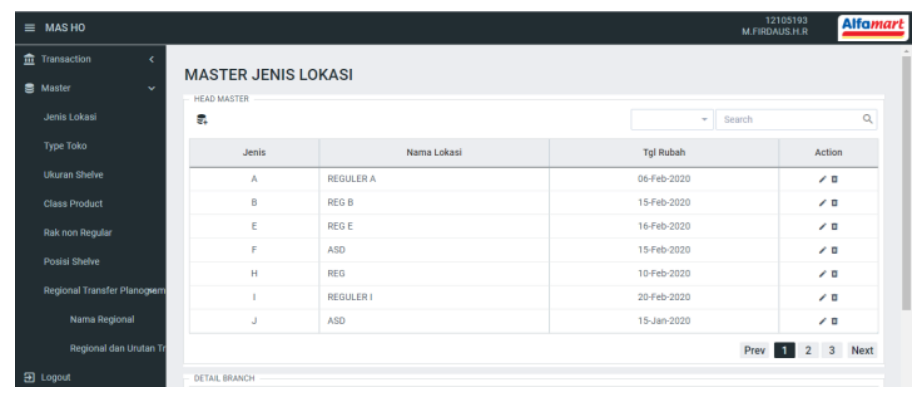

Gambar 5 Halaman Menu Jenis Lokasi

Gambar 5 merupakan halaman menu master jenis lokasi. Dalam menu ini terdapat jenis lokasi serta nama lokasi. Pada menu ini user dapat menjalankan fungsi lihat data, tambah data, edit data dan hapus data. Pada master jenis lokasi ini user akan menginputkan jenis lokasi dan nama lokasi yang akan digunakan untuk planogram. 


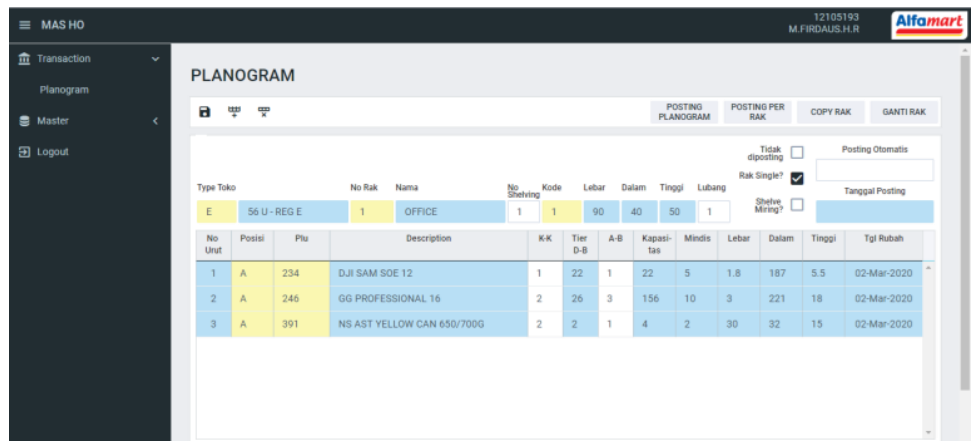

Gambar 6 Halaman Utama Planogram

Gambar 6 merupakan halaman utama planogram. Pada menu planogram ini user dapat menjalankan fungsi lihat data, tambah data, edit data dan hapus data. Jika user ingin melihat data planogram maka user harus memasukkan data tipe toko, nomor rak dan nomor shelve pada form yang ada dalam menu ini. Jika data yang telah dimasukkan tersebut sesuai dengan database maka data planogram akan muncul sesuai dengan tipe toko, nomor rak dan nomor shelve tersebut. Jika user ingin menambahkan data planogram maka user harus menambahkan data master karena data-data planogram ini diambil dari data master.

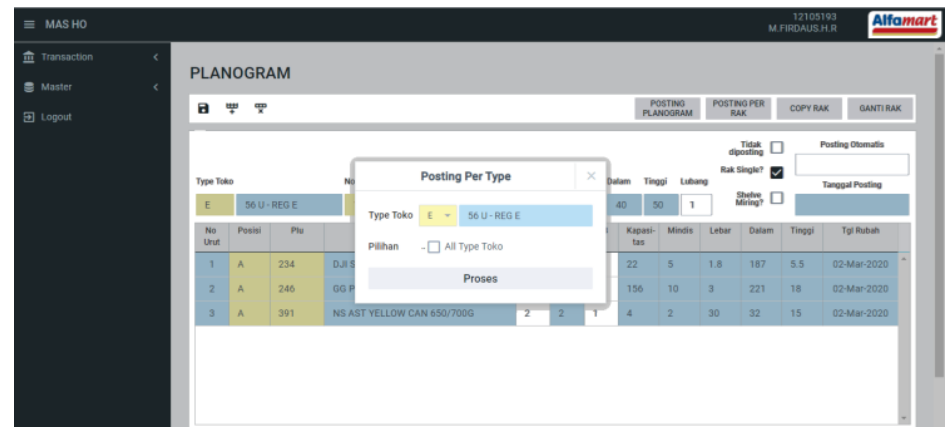

Gambar 7 Halaman Posting Planogram

Gambar 7 merupakan halaman posting planogram yang terdapat pada menu planogram. Fungsi dari posting planogram ini yaitu menyalin data dari tabel head_temporary dan det_temporary ke tabel head_t dan det_t. Jadi sebelum planogram diposting, data-data planogram disimpan pada tabel temporary. User dapat memilih data tertentu yang ingin diposting yaitu dengan memasukkan satu tipe toko, tetapi jika user ingin posting semua data planogram maka pilih all type toko. Data planogram yang diposting berdasarkan tipe toko yang telah diinput oleh $u$ ser.

Kode Program 1 Controller Fungsi Get Data pada Modul Jenis Lokasi

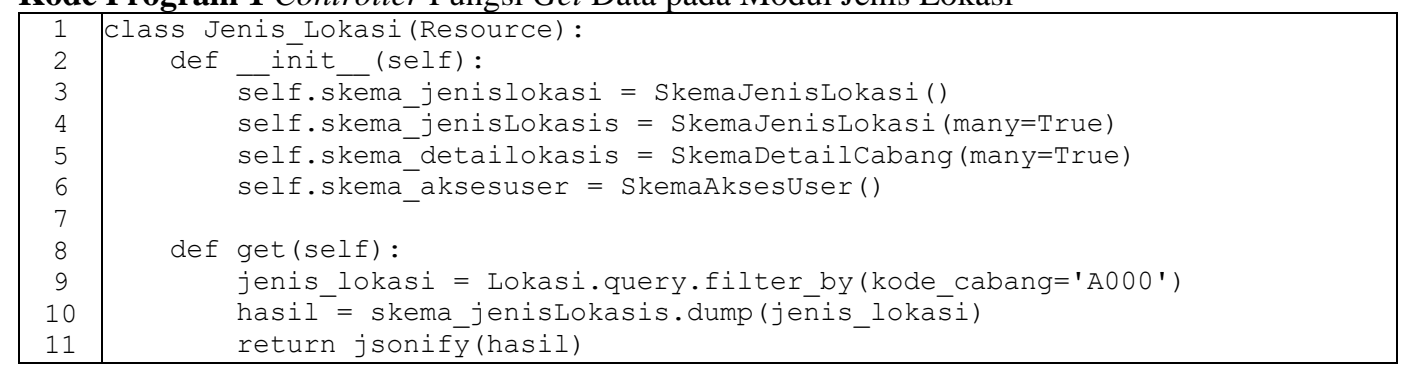

Kode program 1 merupakan fungsi untuk menampilkan data pada modul Jenis Lokasi. Pada saat menampilkan data pada modul ini menggunakan skema dan menggunakan dump untuk menampilkan skema tersebut. Setelah proses dump, hasil tersebut diubah ke bentuk json dengan code 
jsonify(). Hasil implementasi Restfull API dapat dilihat pada fungsi get pada gambar tersebut. Fungsi tersebut nantinya akan dilempar ke tampilan web melalui request HTTP.

Kode Program 2 Controller Fungsi Get Data Posisi pada Modul Planogram

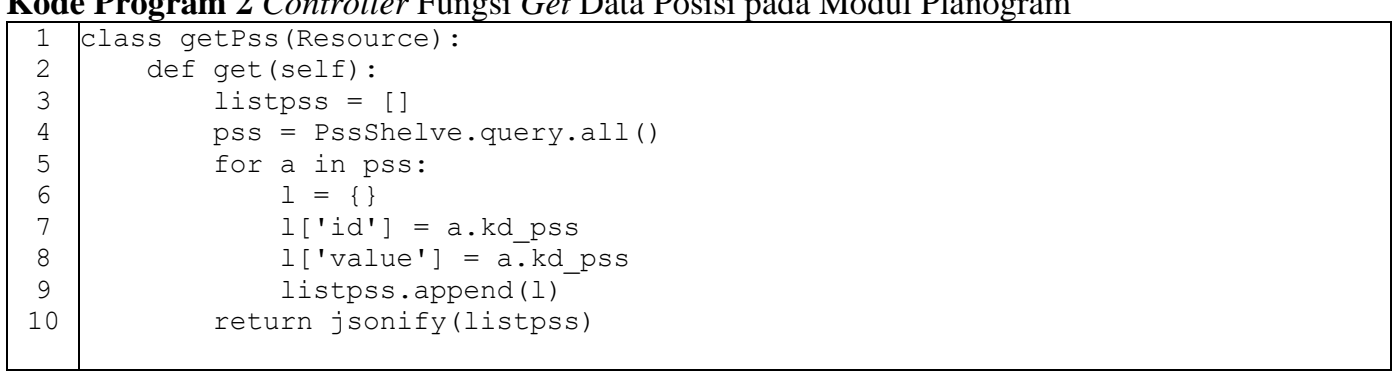

Kode program 2 berfungsi untuk menampilkan data posisi pada modul Planogram. Dalam fungsi ini terdapat list kosong untuk menampung data posisi yang akan ditampilkan. Kemudian setelah dilakukan query data maka data tersebut ditambahkan pada list dan hasilnya diubah ke bentuk json. Hasil implementasi Restfull API dapat dilihat pada fungsi get pada gambar tersebut. Fungsi tersebut nantinya akan dilempar ke tampilan web melalui request HTTP.

\section{d. Pengujian}

Pengujian sistem pada aplikasi ini dilakukan menggunakan metode black box testing dan user acceptance testing.

\section{Black box Testing}

Black box testing merupakan metode pengujian program yang lebih menekankan pada fungsional program yang diuji dan pemeriksaan proses input dan data output pada program [10]. Berikut ini adalah hasil pengujian yang telah dilakukan dengan metode black box pada penelitian ini.

Tabel 2. Pengujian pada Halaman Login

\begin{tabular}{|c|l|l|l|l|c|}
\hline No. & Fungsi & \multicolumn{1}{|c|}{ Inputan } & $\begin{array}{l}\text { Output yang } \\
\text { Diharapkan }\end{array}$ & \multicolumn{1}{c|}{ Output } & Hasil \\
\hline 1 & Login & $\begin{array}{l}\text { Username dan Password } \\
\text { tidak diisi }\end{array}$ & $\begin{array}{l}\text { Muncul pesan } \\
\text { kesalahan }\end{array}$ & $\begin{array}{l}\text { Muncul pesan “Username } \\
\text { dan Password harus diisi!” }\end{array}$ & Valid \\
\hline 2 & Login & $\begin{array}{l}\text { Username diisi data } \\
\text { yang tidak sesuai }\end{array}$ & $\begin{array}{l}\text { Muncul pesan } \\
\text { kesalahan }\end{array}$ & $\begin{array}{l}\text { Muncul pesan "Data tidak } \\
\text { valid!” }\end{array}$ & Valid \\
\hline 3 & Login & $\begin{array}{l}\text { Password diisi data } \\
\text { yang tidak sesuai }\end{array}$ & $\begin{array}{l}\text { Muncul pesan } \\
\text { kesalahan }\end{array}$ & $\begin{array}{l}\text { Muncul pesan "Username } \\
\text { atau Password salah!” }\end{array}$ & Valid \\
\hline 4 & Login & $\begin{array}{l}\text { Username dan Password } \\
\text { diisi data yang sesuai }\end{array}$ & Berhasil login & $\begin{array}{l}\text { Berhasil login dan masuk } \\
\text { ke halaman utama }\end{array}$ & Valid \\
\hline
\end{tabular}

Tabel 3. Pengujian pada Halaman Master Data Jenis Lokasi

\begin{tabular}{|c|c|l|l|l|c|}
\hline No. & Fungsi & \multicolumn{1}{|c|}{ Inputan } & $\begin{array}{l}\text { Output yang } \\
\text { Diharapkan }\end{array}$ & Output & Hasil \\
\hline 1 & Insert & $\begin{array}{l}\text { Salah satu maupun } \\
\text { semua field pada form } \\
\text { tidak diisi }\end{array}$ & $\begin{array}{l}\text { Muncul pesan } \\
\text { kesalahan }\end{array}$ & $\begin{array}{l}\text { Muncul pesan "Data } \\
\text { Kosong!" }\end{array}$ & Valid \\
\hline 2 & Insert & $\begin{array}{l}\text { Mengisi form dengan } \\
\text { data jenis lokasi yang } \\
\text { sudah ada dalam } \\
\text { database }\end{array}$ & $\begin{array}{l}\text { Muncul pesan } \\
\text { duplikat data }\end{array}$ & $\begin{array}{l}\text { Muncul pesan "Data Jenis } \\
\text { Lokasi sudah ada!" }\end{array}$ & Valid \\
\hline
\end{tabular}




\begin{tabular}{|c|l|l|l|l|l|}
\hline 3 & Insert & $\begin{array}{l}\text { Form diisi data yang } \\
\text { sesuai dengan } \\
\text { ketentuan }\end{array}$ & $\begin{array}{l}\text { Berhasil } \\
\text { menambahkan } \\
\text { data }\end{array}$ & $\begin{array}{l}\text { Muncul pesan "Data } \\
\text { berhasil diinsert!" dan data } \\
\text { berhasil ditambahkan }\end{array}$ & Valid \\
\hline
\end{tabular}

Tabel 4. Pengujian pada Halaman Planogram

\begin{tabular}{|c|l|l|l|l|l|}
\hline No. & Fungsi & \multicolumn{1}{|c|}{ Inputan } & $\begin{array}{l}\text { Output yang } \\
\text { Diharapkan }\end{array}$ & \multicolumn{1}{|c|}{ Output } & Hasil \\
\hline 1 & $\begin{array}{l}\text { Lihat } \\
\text { Data }\end{array}$ & $\begin{array}{l}\text { Salah satu field tidak } \\
\text { diisi }\end{array}$ & $\begin{array}{l}\text { Muncul pesan } \\
\text { kesalahan }\end{array}$ & $\begin{array}{l}\text { Muncul keterangan } \\
\text { "Tidak ada data" }\end{array}$ & Valid \\
\hline 2 & $\begin{array}{l}\text { Lihat } \\
\text { Data }\end{array}$ & $\begin{array}{l}\text { Data yang diisi tidak } \\
\text { sesuai dengan } \\
\text { database }\end{array}$ & $\begin{array}{l}\text { Muncul pesan } \\
\text { kesalahan }\end{array}$ & $\begin{array}{l}\text { Muncul keterangan } \\
\text { "Tidak ada data" }\end{array}$ & Valid \\
\hline 4 & Insert & $\begin{array}{l}\text { Data diisi sesuai } \\
\text { dengan ketentuan }\end{array}$ & $\begin{array}{l}\text { Berhasil } \\
\text { menambahkan } \\
\text { data }\end{array}$ & $\begin{array}{l}\text { Muncul pesan "Data } \\
\text { berhasil disimpan!" } \\
\text { dan data berhasil } \\
\text { ditambahkan }\end{array}$ & Valid \\
\hline
\end{tabular}

Berikut ini merupakan tampilan pengujian yang dilakukan menggunakan metode Black Box.

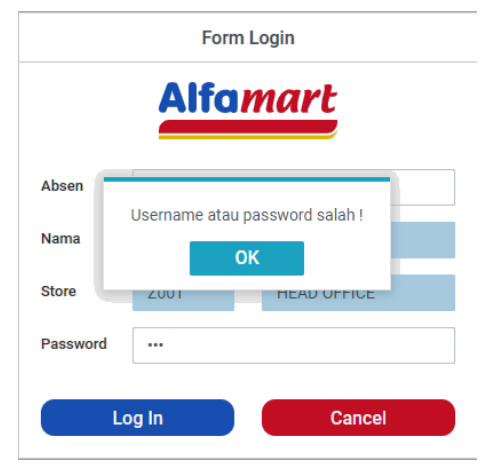

Gambar 9 Tampilan Pengujian Login

Gambar 9 merupakan tampilan pengujian pada halaman login ketika data password diisi dengan data yang tidak sesuai. Output dari pengujian tersebut yaitu muncul pesan seperti pada gambar diatas dan output sesuai dengan yang diharapkan.

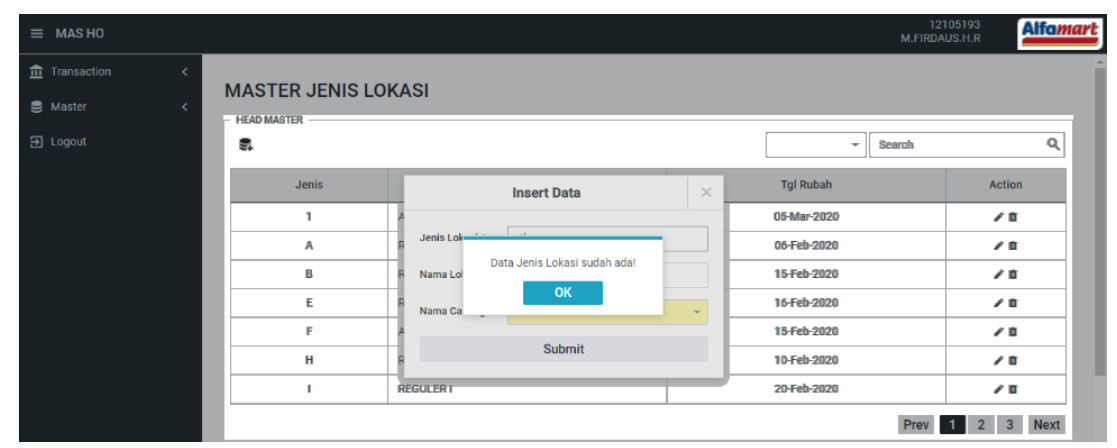

Gambar 10 Tampilan Pengujian Master Jenis Lokasi 
Gambar 10 merupakan tampilan pengujian pada halaman data master jenis lokasi pada fungsi insert data ketika data jenis lokasi diisi dengan data yang sudah ada dalam database. Output dari pengujian tersebut yaitu muncul pesan seperti pada gambar diatas dan output sesuai dengan yang diharapkan.

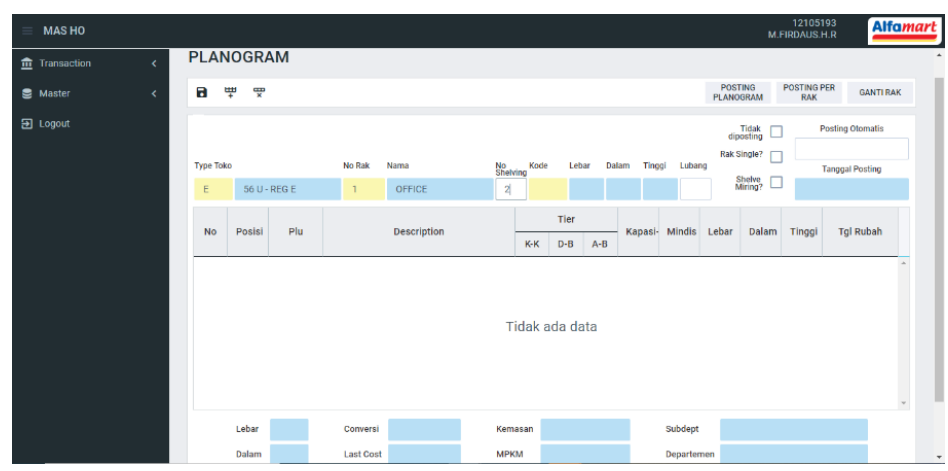

Gambar 11 Tampilan Pengujian Planogram

Gambar 11 merupakan tampilan pengujian pada halaman planogram pada fungsi lihat data ketika data yang diisi tidak sesuai dengan database. Output dari pengujian tersebut yaitu muncul keterangan seperti pada gambar diatas dan output sesuai dengan yang diharapkan.

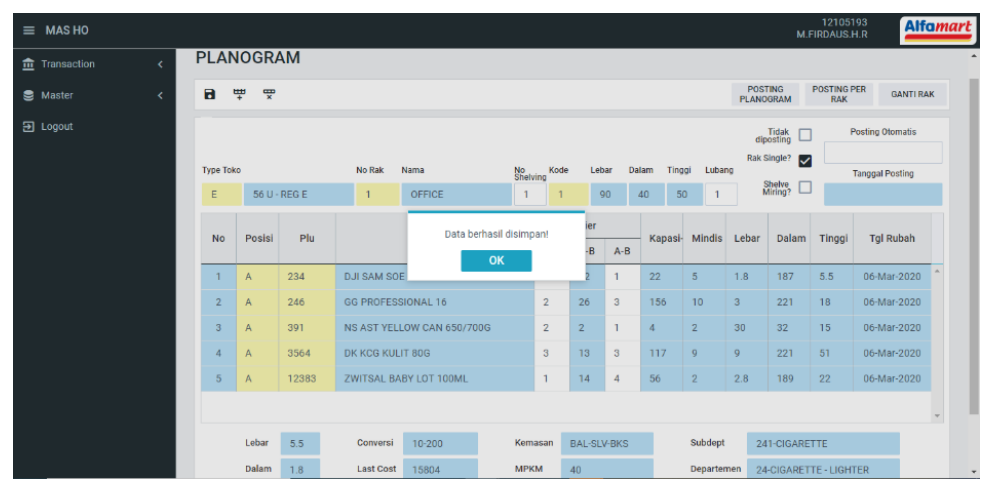

Gambar 12 Tampilan Pengujian Planogram

Gambar 12 merupakan tampilan pengujian pada halaman planogram pada fungsi insert data ketika data yang diisi sesuai dengan database. Output dari pengujian tersebut yaitu muncul data sesuai dengan inputan tersebut dan output sesuai dengan yang diharapkan.

\section{User Acceptacne Testing (UAT)}

User acceptacne testing merupakan pengujian yang melibatkan user untuk mengetahui apakah sistem yang telah dibuat sudah sesuai dengan kebutuhan maupun berfungsi sesuai dengan yang diharapkan. User yang terlibat dalam pengujian UAT ini yaitu 2 Senior Programmer Analyst, 3 Quality Assurance dan 15 karyawan bagian marketing. Hasil pengujian dapat dilihat pada tabel 5 .

Tabel 5. Hasil Pengujian dengan User Acceptance Testing

\begin{tabular}{|c|c|c|c|c|c|c|c|c|}
\hline \multirow[t]{2}{*}{ No } & \multirow[t]{2}{*}{ Pertanyaan } & \multicolumn{5}{|c|}{ Jawaban } & \multirow[t]{2}{*}{ Jumlah } & \multirow[t]{2}{*}{ Indeks } \\
\hline & & Ax5 & Ax4 & Ax3 & $\mathrm{Ax} 2$ & Ax1 & & \\
\hline 1 & $\begin{array}{lr}\text { Apakah aplikasi yang } \\
\text { telah dibuat } \\
\text { digunakan } & \text { dengan }\end{array}$ & 14 & 6 & & & & 94 & $94 \%$ \\
\hline
\end{tabular}




\begin{tabular}{llllll}
\hline \multicolumn{2}{l}{$\begin{array}{l}\text { mudah dan ringan oleh } \\
\text { user? }\end{array}$} & & & 95 & $95 \%$ \\
\hline 2. & $\begin{array}{l}\text { Apakah aplikasi yang } \\
\text { telah dibuat sudah sesuai } \\
\text { dengan kebutuhan yang } \\
\text { telah ditentukan? }\end{array}$ & & & & \\
\hline 3. & $\begin{array}{l}\text { Apakah aplikasi yang } \\
\text { telah dibuat dapat } \\
\text { membantu memudahkan } \\
\text { pekerjaan karyawan }\end{array}$ & & & 94 & $94 \%$ \\
yang bersangkutan? & & & & \\
Apakah aplikasi yang & 13 & 7 & 93 & $93 \%$ \\
telah dibuat dapat \\
mempercepat pekerjaan \\
pengguna dalam \\
mengelola data \\
planogram?
\end{tabular}

Berikut ini merupakan penjelasan pada tabel 5. Pada kolom jawaban Ax5 merupakan sangat setuju, Ax4 merupakan setuju, Ax3 merupakan cukup, Ax3 merupakan tidak setuju dan Ax1 merupakan sangat tidak setuju. Kolom jumlah merupakan total perhitungan nilai jawaban. Kolom indeks merupakan presentase jumlah / total sample user* 100.

Berdasarkan Tabel 5 dapat dihitung nilai rata-rata pada jawaban pertama adalah 18,8 maka persentasenya adalah 94\%, nilai rata-rata pada jawaban kedua adalah 19 maka persentasenya adalah 95\%, nilai rata-rata pada jawaban ketiga adalah 18,8 maka persentasenya adalah $94 \%$ dan nilai rata-rata pada jawaban keempat adalah 18,6 maka persentasenya adalah $93 \%$. Berdasarkan perhitungan User Acceptance Test, indeks yang didapatkan untuk pengujian User Acceptance Test adalah sebesar 94\%. Berdasarkan analisa pengujian User Acceptance Test yang telah dilakukan didapatkan bahwa sistem Master Data Planogram berbasis web ini dapat membantu menyelesaikan permasalahan yang ada, fungsi-fungsi yang terdapat di dalam sistem tersebut juga sudah bekerja dengan baik, Master Data Planogram berbasis web ini juga memiliki kemudahan dalam penggunaanya.

\section{KESIMPULAN DAN SARAN}

Hasil penelitian ini yaitu aplikasi master data planogram berbasis web. Metode yang digunakan pada penelitian ini adalah RESTful API yaitu implementasi dari web service yang bekerja melalui link HTTP. Bahasa yang digunakan pada aplikasi ini merupakan bahasa yang sedang banyak dipakai pada saat ini yaitu python dengan menggunakan framework Flask. Aplikasi ini bertujuan untuk memudahkan user untuk memasukkan data-data master yang akan dipakai pada saat pembuatan planogram.

Saran dari penulis untuk pengembangan aplikasi ini yaitu:

- Penggunaan python Flask bisa dikembangkan lebih dalam dan dapat ditambahkan JSON Web Token untuk melindungi API agar tidak mudah diakses oleh orang yang tidak berkepentingan

- Mungkin kedepannya aplikasi ini dapat dikembangkan berbasis mobile dan dibuat lebih dinamis serta efisien dengan versi mobile. 


\section{DAFTAR PUSTAKA}

[1] D. Hikmawati and C. Nuryakin, "Keberadaan Ritel Modern dan Dampaknya terhadap Pasar Tradisional di DKI Jakarta," J. Ekon. dan Pembang. Indones., vol. 17, no. 2, p. 195, 2017, doi: 10.21002/jepi.v17i2.768.

[2] "Identitas Perusahaan Alfamart," Alfamartku. [Online]. Available: http://corporate.alfamartku.com/identitas-perusahaan. [Accessed: 08-Oct-2019].

[3] S. S. Widodo, "Pengaruh Discount, Display Produk dan Lokasi Toko terhadap Keputusan Pembelian di Toko D’Sport Kediri," Simki-Economic, vol. 01, no. 01, 2017.

[4] R. Haryanto, T. Octavia, and R. Sugianto, "Pengaruh Peletakan Display Produk Berdasarkan Prinsip 5R dan Planogram terhadap Peningkatan Penjualan : Studi Kasus pada Ritel X di Lamongan,” J. Titra, vol. 6, no. 2, pp. 385-392, 2018.

[5] G. A. Priyatna Zaman, "Perancangan Dan Implementasi Web Service sebagai Media Pertukaran Data pada Aplikasi Permainan,” J. Inform., vol. 11, no. 2, pp. 22-30, 2017.

[6] M. Agus, A. Teknik, S. T. T. Terpadu, and N. Fikri, "Analisis dan Perancangan Representational State Transfer (REST) Web Service Sistem Informasi Akademik STT Terpadu Nurul Fikri Menggunakan YII Framework," J. Teknol. Terpadu, vol. 2, no. 2, 2016.

[7] F. N. Rofiq and A. Susanto, "Implementasi RESTful Web Service untuk Sistem Penghitungan Suara Secara Cepat pada Pilkada," EKSPLORA Inform., vol. 6, no. 2, pp. 159-168, 2017.

[8] A. Rahmatulloh, H. Sulastri, and R. Nugroho, "Keamanan RESTful Web Service Menggunakan JSON Web Token ( JWT ) HMAC SHA-512," JNTETI, vol. 7, no. 2, p. 132, 2018.

[9] F. Esti, M. Rizal, E. Hari, D. Rosal, M. Setiadi, and C. Atika, "Implementasi E-arsip Untuk Penyimpanan Dokumen Digital Pada PT BPD Jateng (Bank Jateng)," Tecno.COM, vol. 18, no. 4, pp. 299-311, 2019.

[10] M. Komarudin, "Pengujian perangkat Lunak metode Black box berbasis partitions pada aplikasi sistem informasi di sekolah," J. Mikrotik, vol. o6, no. 3, pp. 02-16, 2016, doi: http://dx.doi.org/10.1016/j.brat.2012.09.004. 